\title{
Editorial: developments at the Annals of regional science 2020-2021
}

\author{
Martin Andersson ${ }^{1,2,3,4}$ - Brian H. S. Kim ${ }^{5}$. Janet E. Kohlhase ${ }^{6}$ \\ Published online: 14 February 2022 \\ (ᄋ) The Author(s), under exclusive licence to Springer-Verlag GmbH Germany, part of Springer Nature 2022
}

\begin{abstract}
The editors-in-chief of the Annals of Regional Science offer an overview and analysis of recent developments at the journal from January 2020 through December 2021, a time period hampered by the COVID-19 pandemic. Annal's Impact Factor increased substantially to 2.646 in 2020. Moreover, submissions increased from pre-COVID times. A new development is the shifting of source regions for articles accepted for publication. For the first time, China tied with the USA to lead the distribution of acceptances by country. Special Issues continue to be important components of the journal.
\end{abstract}

JEL Classification R0 $\cdot \mathrm{Q} 0 \cdot \mathrm{H} 0 \cdot \mathrm{J} 0 \cdot \mathrm{O} 0 \cdot \mathrm{Y} 9$

\section{Introduction}

This is the second in a new series written by the editors of the Annals of Regional Science about the state of the journal during the most recent time period. The pioneering first editorial (Andersson et al. 2020) was a detailed overview of the workings of Annals of Regional Science from 1967 to the beginning of January 2020 , just before COVID-19 became a pandemic. The second editorial will be a much shorter piece that traces new developments for the time period January 1 ,

Janet E. Kohlhase

jkohlhase@uh.edu

1 Department of Industrial Economics, Blekinge Institute of Technology (BTH), Karlskrona, Sweden

2 Swedish Entrepreneurship Forum, Stockholm, Sweden

3 Research Institute of Industrial Economics, Stockholm, Sweden

4 CIRCLE, Lund University, Lund, Sweden

5 Department of Agricultural Economics and Rural Development, Seoul National University, Seoul, Korea

6 Department of Economics, University of Houston, Houston, TX, USA 
2020-December 31, 2021. The Annals of Regional Science has three main editors (editors-in-chief) representing broad regions around the world including North America, Europe, and Asia: Martin Andersson is from Sweden, Brian Kim from Korea, and Janet Kohlhase from the USA. The supporting board of 36 associate editors similarly comes from 11 countries representing North America, Europe, Asia and Australia. The Board is composed of junior (associate professor level or equivalent) and senior scholars doing research in regional science and related fields.

\section{COVID-19 and Annals of Regional Science}

Most parts of the world went into various degrees of lockdown due to the COVID-19 pandemic in the first few months of 2020 through 2021 (and likely beyond). The lockdowns had dire consequences on face-to face academic meetings. The Western Regional Science Association (WRSA), for which the Annals of Regional Science is the official journal, canceled its March 2020 meetings in Hawaii and delayed the bestowing of awards for new scholars and dissertation students as well as the Presidential Address into the summer of 2020. The 2021 WRSA meeting went virtual as did most academic meetings around the world. At the writing of this editorial, about two years later, we hope to hold the WRSA meetings in February 2022 in person, the first time in two years.

The editors expected submissions to suffer due to COVID-19 but were surprised that the number of submissions to Annals of Regional Science in 2020 exceeded the number pre-COVID in 2019 by about $10 \%$ and still exceeded the 2019 amount by about 6\% in 2021. But where Annals of Regional Science definitely suffered was in obtaining referees for the submitted papers. Many of those invited to review declined because of COVID-related issues, and hence, we had a slight increase in the time papers took going through the pipeline from submission to first decision in 2020 and a larger increase in time to first decision in 2021. We are working on improving the turn-around time.

\section{Update on developments at Annals of Regional Science}

\subsection{Continued rise in impact factor}

The Impact Factor (IF) published by Clarivate Analytics (previously Thomson Reuters) is a widely used indicator of a journal's prestige and overall impact of scholarly research. We are pleased to report that Annals of Regional Science' Impact Factor (IF) for 2020 is 2.646 up from 1.750 in 2019 and 1.075 in 2018. It should be noted that the available 2020 Impact Factor (counting citations in 2020 to articles published in Annals of Regional Science in 2019 and 2018) does 
not yet have much influence from the productivity changes during the pandemic. Based on our 2020 IF, we are in the 2 nd quartile of all journals IF's for economics and geography and in the 3rd quartile for regional \& urban planning and environmental studies.

\subsection{Broad range of topics and authors}

As described in the "term analysis" reported in our first review (Andersson et al. 2020), Annals of Regional Science publishes articles on a broad range of topics in regional science. Supporting that view is the composition of the top five most downloaded papers and cited papers published recently in the Annals of Regional Science and shown in Table 1. Panel A shows for the time period 2018-2021 that four of the top five most downloaded papers are concerned with the economics and geography of cities. Giuliano et al. (2019) trace the role and nature of agglomeration economies in the evolution of urban form using Los Angeles as a case study. Vos et al. (2018) examine how increased working from home may lead workers to be willing to make longer commutes to the workplace. Lai

Table 1 The five most downloaded papers published in the Annals of Regional Science, 2018-2021 and five most cited papers published in 2018-2019

Title Authors

Panel A: Most downloaded from publications 2018-2021

1. Agglomeration economies and evolving urban form

2. Working from home and the willingness to accept a longer commute

3. The determination of the "true" property boundary in planned development: a Coasian analysis

4. Inside and outside the black box: organization of interdependencies

5. Amenities and the geography of innovation: evidence from Chinese cities

Panel B: Most cited from publications 2018-2019

1. Regional economic resilience: the experience of the Italian local labor systems

2. Territorial capital and the resilience of European regions

3. Innovation and regional economic resilience: an exploratory analysis

4. Economic resilience in Great Britain: the crisis impact and its determining factors for local authority districts

5. Measuring resilience to economic shocks: an application to Spain
Genevieve Giuliano, Sanggyun Kang and Quan Yuan

Duco Vos, Evert Meijers and Maarten Ham

Lawrence W. C. Lai et al

Åke E. Andersson and Börje Johansson

Min Zhang, Mark D. Partridge and Huasheng Song

Alessandra Faggian, Roberta Gemmiti, Timothy Jaquet \& Isabella Santini

Ugo Fratesi \& Giovanni Perucca

Gillian Bristow and Adrian Healy

Anastasios Kitsos and Paul Bishop

A. M. Angulo, J. Mur and F. J. Trivez 
et al (2018) argue that to resolve disputes over land boundaries under conditions of positive transaction costs according to what the authors term the third Coase Theorem, the choice may be to use the courts instead of the market. Zhang et al (2020) discuss how amenities in cities may act as a magnet to innovative firms. The paper by Bristow and Healy (2018) looks at regions and how innovation may contribute to resilience. It is interesting to note that the first editorial on the state of Annals of Regional Science (Andersson et al. 2020) was in the top 10 most downloaded articles during the time period analyzed.

Panel B of Table 1 shows that the five most cited papers published in Annals of Regional Science 2018-2019 are concerned with various regional issues in Europe. We look at citations to papers published during the two-year time period 2018-2019 since those citations form the basis of our 2020 Impact Factor. All of the top-five cited papers appeared in a Special Issue of Annals of Regional Science, "Regional Determinants of Economic Resilience," edited by guest editors Paolo Di Caro and Ugo Fratesi and published in 2018. The papers examine various regional aspects of the global economic crisis of 2007-2008. Faggian et al. (2018) focus on local labor systems (LLS) in Italy and examine two dimensions of resilience, i.e., resistance and recovery. Fratesi and Perucca (2018) examine the differential impact of the 2007-2008 crisis in Europe, by examining the regional endowment of structural territorial assets, those which have been labeled as "territorial capital." Bristow and Healy (2018) provide empirical analysis of the relationship between regional innovation capacity and the resilience of European regions to the economic crisis of 2007-2008. Kitsos and Bishop (2018) examine the crisis' impact on employment in Great Britain's Local Authority Districts (LADs) using the concept of economic resilience. The study finds a significant effect for initial economic conditions, human capital, age structure, urbanization and geography. Angulo et al. (2018) evaluate Spanish regions' resistance to the economic crisis under three main resilience notions: adaptative, engineering and ecological. Among their findings is that the probability of a lower "drop" in growth than average increases for those regions specialized in the service sector before the crisis.

Table 2 Distribution of papers accepted January 2020December 2021 by country of residence of corresponding author, top 10 countries

\begin{tabular}{ll}
\hline Country & $\begin{array}{l}\text { Acceptances (as \% } \\
\text { of total accept- } \\
\text { ances) }\end{array}$ \\
\hline China & 15 \\
USA & 15 \\
Spain & 9 \\
UK & 6 \\
Brazil & 5 \\
Italy & 5 \\
Sweden & 5 \\
Chile & 4 \\
Japan & 4 \\
Netherlands & 4 \\
\hline
\end{tabular}




\subsection{Global distribution of authors}

Annals of Regional Science receives submissions from authors around the world, and in the time period analyzed here-January 1, 2020-December 31, 2021-the majority of submissions are from China, the USA and Europe. Table 2 shows the distribution of the country of residence of the corresponding authors of accepted papers. Altogether the top 7 countries accounted for about $60 \%$ of the total acceptances in the time period analyzed. We find that China ties with the USA in the top percent of total acceptances-15\% each-granted during the time period, followed by Spain at $9 \%$ and the UK at $6 \%$. Another noteworthy finding is that two countries in South America are for the first time in the top 10 nations with acceptances from Annals of Regional Science: Brazil had 5\% and Chile $4 \%$ of the total acceptances January 1, 2020-December 31, 2021.

\subsection{Special issues}

Annals of Regional Science continued its history of publishing high-quality special issues on important topics in regional science during 2020 and 2021. Special issues published in 2020 include (guest editors in parentheses):

- 17th International Workshop on Spatial Econometrics and Statistics (Rachel Guillain and Julie Le Gallo)

- Stated and revealed locational preferences of firms: a national scale perspective (Dario Musolino, Ilaria Mariotti and Aleid E. Brouwer)

There are several special issues in the pipeline, and we describe some of them here. "Spotlight on the region" is a collection of state-of-the-art papers in regional science honoring the memory of former Annals of Regional Science editor Roger Stough. "COVID-19: shock, recovery and sustainability-Asian perspective" analyzes the impacts of COVID-19 on Asian economies. "Entrepreneurial Territories: measures, determinants and outcomes" explores many aspects of entrepreneurship across urban and regional landscapes. "Supporting the regional circular economy and sustainability" examines how to define, measure, and analyze the regional circular economy as an alternative to traditional linear economic systems.

For special issues, the editors-in-chief act as coordinating editors with the guest editors. We EICs welcome proposals for high-quality special issues on important and timely topics in regional science. Interested researchers may contact the EICs via email for further information.

\subsection{Opportunities for junior scholars}

Annals of Regional Science has a tradition of publishing papers written by early scholars, especially those who win prizes at the WRSA annual meetings. The Tiebout prize is awarded to the best paper submitted by a full-time $\mathrm{PhD}$ student to a 
competition held by WRSA each year with awards announced at the WRSA annual meetings. See the WRSA website for further details (https:/www.wrsaonline.org/ newsite/call-for-tiebout-submissions/). The Stough-Johansson Springer Award is awarded annually for the best paper presented by an early career scholar (no more than five years post-PhD) at the annual meeting of the WRSA. See the Annals of Regional Science website for further details (https://www.springer.com/journal/168/ updates/18927090). Winners of both awards are encouraged to submit their papers to Annals of Regional Science where papers will undergo the normal review.

\section{Concluding remarks}

We believe that the Annals of Regional Science continues on a good trajectory, despite slight setbacks from adjusting to the COVID-19 pandemic. The EICs continue to support the journal's positive development and look for submissions that push the frontier of regional science. Submissions on current issues such as COVID19 impacts on housing and labor markets in cities and regions as well as COVID19 impacts on government provision of public goods are encouraged. An important component is how workers' commutes may change with increasing tastes for working from home. Related issues concern how firm location may change with changing demand for working from home as well as the disruptions in the supply chain that have been prominent in the COVID period. Other current topics of particular interest to the editors include regional and urban impacts of climate change and how social inequalities may exacerbate impacts. In particular, regional mobility and energy usage may change drastically. Urban-rural conflicts are likely to increase in all these scenarios and are also topics of interest to the editors.

\section{References}

Andersson M, Kim HK, Kohlhase J (2020) Editorial annals of regional science. Ann Reg Sci 64(1):1-8

Andersson A, Johansson B (2018) Inside and outside the black box: organization of interdependencies. Ann Reg Sci 61(31):501-516

Angulo AM, Mur J, Trívez FJ (2018) Measuring resilience to economic shocks: an application to Spain. Ann Reg Sci 60(2):349-373

Bristow G, Healy A (2018) Innovation and regional economic resilience: an exploratory analysis. Ann Reg Sci 60(2):265-284

Faggian A, Gemmiti R, Jaquet T, Santini I (2018) Regional economic resilience: the experience of the Italian local labor systems. Ann Reg Sci 60(2):393-410

Fratesi U, Perucca G (2018) Territorial capital and the resilience of European regions. Ann Reg Sci 60(2):241-264

Giuliano G, Kang S, Yuan Q (2019) Agglomeration economies and evolving urban form. Ann Reg Sci 63:377-398

Kitsos A, Bishop P (2018) Economic resilience in Great Britain: the crisis impact and its determining factors for local authority districts. Ann Reg Sci 60(2):329-347

Lai LWC et al (2018) The determination of the "true" property boundary in planned development: a Coasian analysis. Ann Reg Sci 61(3):479-498

Vos D, Meijers E, van Ham M (2018) Working from home and the willingness to accept a longer commute. Ann Reg Sci 61(2):375-398 
Zhang M, Partridge MD, Song H (2020) Amenities and the geography of innovation: evidence from Chinese cities. Ann Reg Sci 65(1):105-145

Publisher's Note Springer Nature remains neutral with regard to jurisdictional claims in published maps and institutional affiliations. 